Research Paper

\title{
Learning Logic Gates Using Augmented Reality
}

\section{Nurul Hidayah Rahani ${ }^{1}$, Aldrin Aran Bilong ${ }^{1}$, Muhammad Rafiq Mat Suruji ${ }^{1}$, Ismail Yusuf Panessai $^{1}$}

${ }^{1}$ Program of Software Engineering, Department of Computing, Faculty of Arts, Computing, and Industry Creative. Universiti Pendidikan Sultan Idris, Malaysia.

Article History

Received:

05.12.2019

Revised:

15.01 .2020

Accepted:

20.02.2020

*Corresponding Author:

Ismail Yusuf Panessai

Email:

ismailyusuf@fskik.upsi.edu.my

This is an open access article, licensed under: $\mathrm{CC}-\mathrm{BY}-\mathrm{SA}$
Abstract: This research is important to enhance students understanding and learning performance in Computer Organization and Architecture subject especially in logic gate circuit topic as student also can improve their knowledge and usage in new technology like AR. The appropriate methodology chosen in development of this research is ADDIE model which is consists of five phases. The application were evaluated by the student who take Computer Organization and Architecture subject in Sultan Idris Education University. By using ADDIE model as its methodology, the planning of this mobile application was successfully proceeding smoothly starting from the analysis phase until evaluation phase. The details gained from the phase of evaluation will be explained through the next chapter of this research. Overall from this research, the AR-LoGates Apps has shown that it is a necessary product by receiving a good reception from students. The results proved that AR-LoGates application can help students in learning especially in easy to understanding the logic gate topic and make the learning become interesting way.

Keywords: ADDIE, Augmented Reality, Logic Gates, Mobile Application. 


\section{Introduction}

In recent years, there has been an increasing interest in applying Augmented Reality (AR) to create unique educational settings which takes advantage of virtual objects or information overlaying physical objects or environments, resulting in a mixed reality in which virtual objects and real environment coexist in a meaningful way to augment learning experiences. The ability to overlay computer graphics onto the real world is commonly called Augmented Reality (AR) that through the use of advances technology an empty space is turned into a very rich educational experience which has been used and misused to describe a wide variety devices and people.

Students who took the courses related to computer or electronics must learn and understand well in the basic of digital system. These digital systems are constructed by using logic gates. A logic gate is simple device that returns some number of outputs. These outputs are determined by a pattern of inputs and rules the gate follows to create a desired result. At their core, gates return either as "true and false" or "on and off". Logic gates are the foundation of not only computational thinking and coding but also apply to electrical engineering and algebraic thinking. Logic gates usually taught in the lectures, but practical skills are required by doing the experiment to get the output. For student in Software Engineering and student under department of Art, Computer, and Creative Industry, this logic gate topic is importance especially for subject "Computer Organization and Architecture".

For the past student, they learn theoretically about logic gate. By learn on theory, it is actually the traditional chalk and talk teaching method and use of static textbooks are failing to engage students and leading to poor learning outcomes. AR is a new form of human-machine interaction that overlays computer-generated information on the real environment. AR enhances the existing environment rather than replaces it which can potentially apply to all human sense, such as hearing, touching and even smelling [1]. In addition to creating virtual objects, AR could also remove real objects from a perceived environment.

In department of Art, Computer, and Creative Industry, Sultan Idris Education University (UPSI), there still less usage of mobile apps on AR technology in education especially in Computer Organization and Architecture subject in logic gates topic which is need more visualizing abstract concepts that shows great potential in education.

This research focused on four points which is to investigate the use of AR technology to attract interest of students in learning Computer Organization and Architecture subject, design logic gate circuit which able to embed in AR technology, develop logic gate circuit using AR technology, and evaluate the AR technology of logic gate circuit in terms of Graphic User Interface, Contents, and Usability (effectiveness, efficiency, and satisfaction). To meet this objectives, current research scope only focus on students who take Computer Organization and Architecture or related subject in Sultan Idris Education University (UPSI).

\section{Literature Review}

This section discuss past research collection which done on existing applications related to the application to be developed. This section contains clarification of the Augmented Reality, Augmented Reality in Education, and logic gate which is the main scope in developing AR for this research. Augmented Reality contains hardware, development platform, tracking, interaction method and authoring solution. These are important in utilize to develop Augmented Reality.

\subsection{Augmented Reality}

AR is accepted as the extension of the virtual reality which expose to the users a perfect interface that mix the real and virtual world together. Palmarini et al. [2] define Augmented Reality as a way to combine the real world and virtual objects in a real environment as to align virtual objects and real worlds, run interactively and in real time. Users can interact through virtual objects placed in real environments around and experience the natural and real human-computer interaction [3]. By using only computer and camera are required to develop a local AR environment. The camera tracks markers within its vision and then presents the scene that the camera capture and corresponding virtual objects represented by simultaneous markers on the computer screen.

\subsection{Augmented Reality in Education}

Augmented reality provides the user a completely different way to interact with the real environment which also known as Mixed Reality (virtual and augmented reality) [4]. Augmented reality (AR) can 
Nurul Hidayah Rahani, Aldrin Aran Bilong, Muhammad Rafiq Mat Suruji, Ismail Yusuf Panessai.

characterize as a specific innovative technology or technologically induced perceptual environment based on the combination of perceived real environment and augmented. AR technology offer a learning medium that is close to the real world [3] and make it possible for the students to play an active role in the learning process [5], [6]. AR is a solid technology that is already used in some creative applications. One area which might significantly benefit in the future from this technology is technology is the education process [7], [8], [9], [10], [11]. AR tools could guide students through learning process in enhanced way, as AR can upgrade traditional books with a digital layer.

\subsection{Logic Gates}

A digital computer uses binary number system for its operation. In the binary system there are only two digits 0 and 1 . The computer receives, stores, understands and manipulates information composed of only $0 \mathrm{~s}$ and $1 \mathrm{~s}$. An electronic circuit which performs a logic operation is called a logic gate.

A logic gate is a basic building block of a digital circuit, which performs a logical operation on one or more binary inputs, and produces a single binary output. Most logic gates, except NOT gate, have two inputs and one output. The status of the terminal at one time is either " 0 " or " 1 ". When the output is " 0 ", it is called "false" and when it is " 1 ", then it is called "true", that is why the name "truth table" comes from. The "truth table" is a table that list all the truth value of the outcome for each of the possible combinations. The status of the terminal will change as the circuit process the data. There are seven basic logic gates which are AND, OR, XOR, NOT, NAND, NOR, and XNOR. The logic gates are used as pinout configuration of some commonly used integrated circuits of 74 series which are 7408 for AND gate, 7432 for OR gate, 7486 for XOR gate, 7404 for NOT gate, 7400 for NAND gate, 7402 for NOR gate, and 747266 for XNOR gate.

\subsection{Instructional Design Model}

An instructional design model is used to define the activities that will guide the development of elearning projects. Aldoobie [12] define the Instructional Design as instructional technology which supported by Mawardi et al. [13] as a well-designed instructional design that will effectively help to achieve the proposed learning results. There is an instructional design model classification in teaching and learning technology which is a class-oriented model, a product-oriented model, and a systemoriented model. There are a few theories in application development such as ADDIE model, ASSURE model, and Hannafin \& Peck model, but in this research author focus on using ADDIE model.

Table 1. ADDIE Model [12]

\begin{tabular}{llll}
\hline \multicolumn{1}{c}{$\begin{array}{c}\text { ADDIE Model } \\
\text { (Aldoobie [13]) }\end{array}$} & \multicolumn{1}{c}{ Advantages } & \multicolumn{1}{c}{ Disadvantage } \\
\hline Phase & 1. Analysis phase & 1. Flexible to learning & 1. Tends to be inefficient \\
2. Design phase & and teaching instruction & because it is not iterative \\
3. Development phase & $\begin{array}{l}\text { 2. The phases clearly } \\
\text { 4. Implementation phase } \\
\text { 5. Evaluation phase }\end{array}$ & $\begin{array}{l}\text { defined facilitates } \\
\text { implementation of } \\
\text { effective training tools }\end{array}$ & \\
& &
\end{tabular}

\section{Methodology}

This section consists the steps or phases as a guideline for the product development. The selection of the methodology is important to ensure that the goals of the research is accurate and clear which also capable of achieving the objectives that required in the beginning of the project. Methodology also referred to the most appropriate method that used to perform a research to answer the problems statement. This section is about the selection of methodology for product development that include instructional design models, comparison of research methodology, and the methodology that developer chose in order to develop the product.

In choosing the development methodology of the product, the systematic work drawing on existing 
Nurul Hidayah Rahani, Aldrin Aran Bilong, Muhammad Rafiq Mat Suruji, Ismail Yusuf Panessai.

knowledge gained from research directing to produce new product in order to improve the matter found. The developer used research framework on ADDIEs' model in developing the product. This framework contains three phases which are analysis phase, development phase, and evaluation phase. In the first analysis phase, developer doing observations of the past research and analyze the user target. In second phase which is development phase, it involved the methodology model which is developer used ADDIE model. This model includes analysis phase, design phase, development phase, implementation phase, and evaluation phase. In the third phase which is evaluation phase, developer used the questionnaire which is qualitative approach to evaluate the product from the user target.

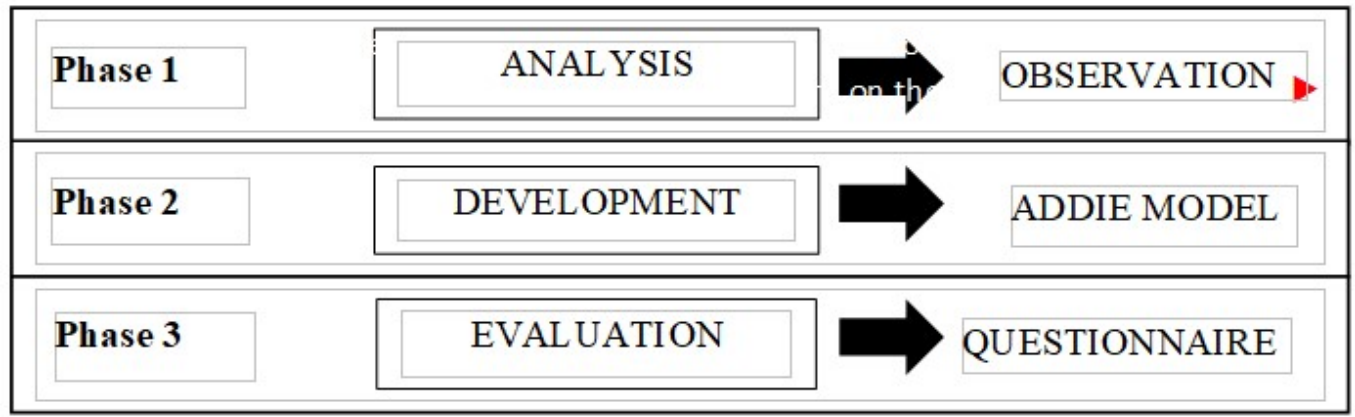

Figure 1. Research Framework

\subsection{Analysis Phase}

Analysis stage is the most important phase in this process. In analysis phase, there are four things that needs to analyse which are analyse the learner, analyse the instructional goals, analyse the developing instructional, and analyse the developing learning objectives. In analysis of the learner, developer need to know about the knowledge that the learners already know about the topic, so developer can make a plan on what the learner learned and know what information the learner needs more. Developer need to know the needs and problems of the learners. In order to analyse the learner, developer used qualitative approach to get the information which make an observation from reading the journals, books, thesis, and trusted online web pages.

Next, in analysis of instructional goals, developer need to identify the goals for the specific instruction of what developer want the learners learn. Developer analyse about Augmented Reality (AR) in education in enhanced interactive learning among student as to achieve effective and efficient learning environment. From the collection of the information, developer was able to identify the advantages and disadvantages of the Augmented Reality especially in education. Developer analyse the instructional goals for student who take subject Computer Organization and Architecture on logic gate circuit topic. From this instructional goal, learner will able to learn logic gate by using Augmented Reality.

Developing instructional analysis is once the developer identifies specific goals, developer started write all the important steps and all the details that the developer need in order to achieve the goals. In analyse developing instructional, developer identify what do developer want the learners learn about logic gate circuit using augmented reality technology. Developer also specify about where and when the student can use that apps. Then, in developing learning objectives, developer define more specific on what the learners should be able to do when the instruction is finished. The objectives need to specify an observable measurable behaviour that show achievement of the goal. Developer need to specify the learning objectives of what the learners get or achieve by using the mobile apps that will be develop.

\subsection{Design Phase}

Design phase is the next phase after analysis phase. This phase is about applying the instruction which is how design instruction can be effective in learning and interaction with the materials that the developer create and focuses on designing the content for the logic gate topic in subject Computer 
Nurul Hidayah Rahani, Aldrin Aran Bilong, Muhammad Rafiq Mat Suruji, Ismail Yusuf Panessai.

AR-LoGates: Learning Logic Gates Using Augmented Reality.

International Journal of Multimedia and Recent Innovation, vol. 2, no. 1, pp. 26-44, March 2020. DOI: 10.36079/lamintang.ijmari-0201.81

Organization and Architecture. In this stage, developer make a content design which assess the learner's outcomes on the logic gate topic. In order to design the content, developer used the information that already collected to make sure the content is strongly related to the instructional and context of the topic logic gate circuit by using augmented reality that will be develop. Developer drafting and prepare the storyboard of the project workflow which involved the image target, marker-based and 3D model of logic gate circuit.

Developer select a form of the course which is a delivery system. Form's course means how the developer going to represent the materials about the topic. Developer select the form of the course that match with the design which is allows the learners to use the mobile phone in tracking or scan the marker-based to track the figure of the augmented reality by using the camera of AR-Vuforia. Learners will be able to create the logic gate circuit by using augmented reality to know the output of the logic gate.

Developer design the marker that will used which is template marker based on the logic gates and appropriate image to easy learner differentiate the marker from others. Then, developer design the model that will used in order to present the object from the augmented reality. Developer design the marker and interface by using Adobe Photoshop and Microsoft PowerPoint as to make the design clear and easy to use.

\subsection{Development Phase}

Development phase is the third phase that depends on the analysis phase and design phase. In this phase, the instructional design need to integrate the technology with the educational setting and process. Developer used the combination of technology requirement and software in this phase to develop the project. In order to develop the materials of the course, developer start developing once the design is satisfied depends on the objectives and instructional design. The software selected in developing this project is Unity 3D, Adobe Photoshop which can be download freely.

Developer used adobe Photoshop to create marker which is template marker-based. Template marker-based that used is consists of simple image inside a black border which is logic gates symbol image. These images were used to ease the learners identify the image in order to create the logic gates circuit. After the images is confirm, developer will print the marker to use for tracking by use the camera of AR-Vuforia. For create model, developer will create it using Unity 3D. Then, developer will develop augmented reality using unity 3D software and create the coding for the application. After all the marker, model is done, developer build an app into Android operating system as the scope of this application is for Android phone.

\subsection{Implementation Phase}

Implementation phase is the phase after development phase which about transforming the plan into action in order to ensure that the delivery of the instruction is effective and efficient. Developer prepare the learners for the product developed. Within preparing the learners, developer have to make sure that the learners already have the mobile phone to try the mobile apps that developed. The learner will use it without any help from developer in order to identify and determine that the product developed had meet the user requirements or not. Learners can give feedback of the product developed so that developer be able to make improvement to the mobile apps developed.

\subsection{Evaluation Phase}

Evaluation phase is the final stage in ADDIE model. Evaluation is important in order to make sure that the developer using the instructional design and materials to meet the learner needs. In this phase, developer have to ensure that the product has reached the learners objectives. Through this evaluation, developer perform a summative evaluation which occurs after the instruction complete in development and implement. Developer have been distributing the questionnaires to 30 students whose taking Computer Organization and Architecture subject in Sultan Idris Education University (UPSI). The questionnaires require the students to answer it by using the Likert Scale with the optionally answer provided in term of usability, functionality, and the accessibility of the product appropriate with the learners.

\section{Development}

This section discuss in detail about design and development of research products according to the 
Nurul Hidayah Rahani, Aldrin Aran Bilong, Muhammad Rafiq Mat Suruji, Ismail Yusuf Panessai.

AR-LoGates: Learning Logic Gates Using Augmented Reality.

International Journal of Multimedia and Recent Innovation, vol. 2, no. 1, pp. 26-44, March 2020. DOI: 10.36079/lamintang.ijmari-0201.81

research methodology selected based on the objectives of the study. This section involved the development phases of the product which contains about the process, icons, interfaces, and also user manual of the product. Besides, this section also discussed about the design of the application that involve the function that collate with each other.

\subsection{Analysis Phase}

Analysis phase is the initial phase where the developer searching the information required to the research title. Through this phase, the developer has concluded two of the instrument which is observation and questionnaire that are help a lot in collecting data requirement. The observation was made from a journal and books reading, including UPSI student who's taking Computer Organization and Architecture subject. Through the collected data requirement, the developer can analyse the results of the research that have been done to define the research goal, objectives, and problem statements in order to continue to the development phase. From analysis phase, the developer had the idea of what the tools and software required to develop the project. Other than that, the developer also follows the ADDIE model regarding to develop the project. The main software that will be used is Unity 3D, Android Studio, Visual Studio and also Vuforia SDK. This software can be used to develop the Augmented Reality Application.

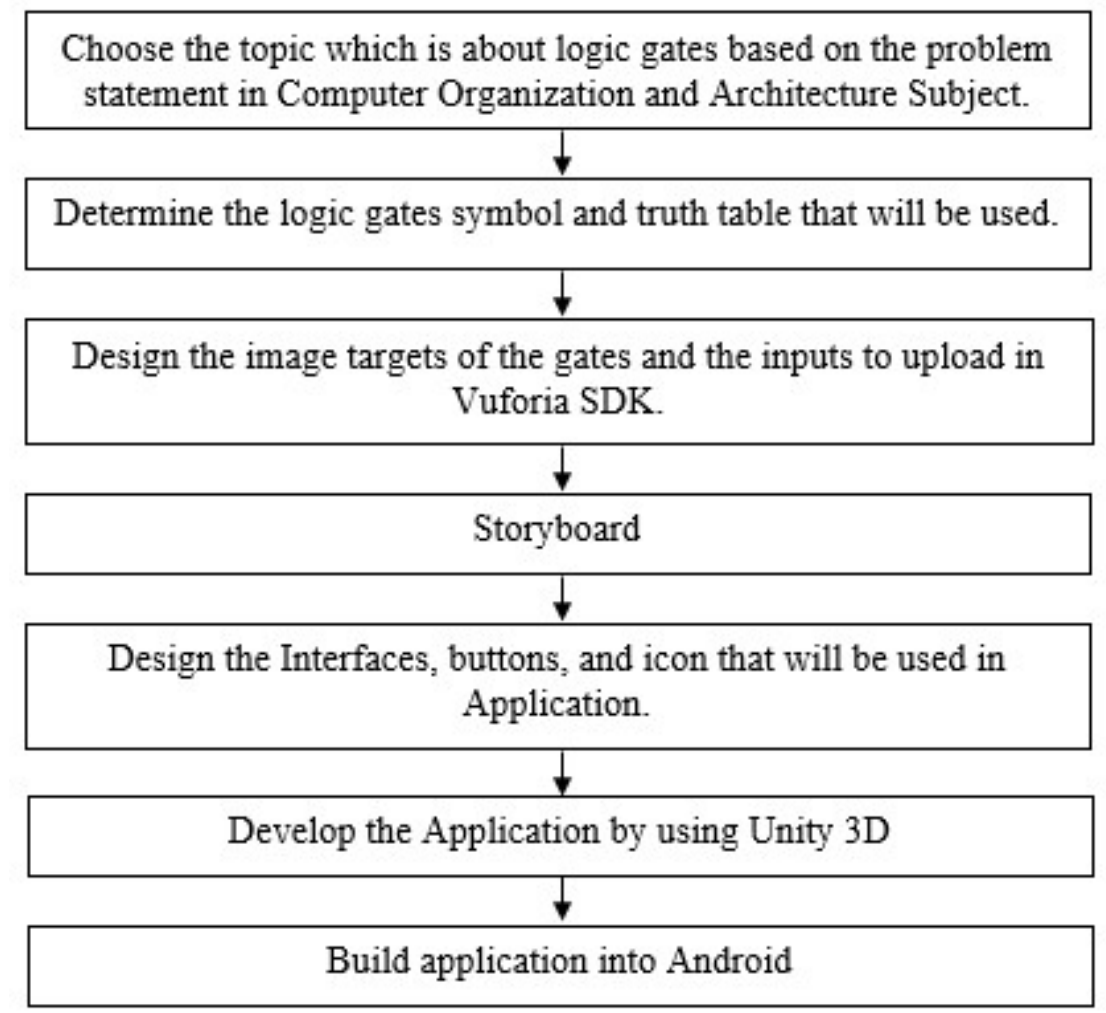

Figure 2. Flowchart of AR-LoGates Development

\subsection{Design Phase}

Design phase about applying the instruction which is how design instruction can be effective in learning and interaction with the materials that the developer create and focuses on designing the content for the logic gate topic in subject Computer Organization and Architecture. In this stage, developer make a content design which assess the learner's outcomes on the logic gate topic. In order to design the content, developer used the information that already collected to make sure the content is strongly related to the instructional and context of the topic logic gate circuit by using augmented reality that 
will be develop. Developer drafting and prepare the storyboard and interfaces for AR-LoGares Apps workflow which involved the image target, marker-based and 3D model of logic gate circuit. The detail of the flowchart, storyboard and interfaces are shown as follow.

Figure 2 shows the flowchart of the software design for develop this project. As figure shown that developer initiated the project with selecting the topic which is about logic gates topic in Computer Organization and Architecture Subject. Next, developer has determined the logic gates involves which are AND gate, OR gate, NOT gate, NAND gate, NOR gate, XOR gate, and XNOR gate. Other than that, developer design the image target by using Microsoft power point and adobe Photoshop, and the 3D object design by using Unity 3D. The development of the application is using Unity 3D. Lastly, developer build this application into the android system by using Android Studio SDK.

\subsubsection{Instructional Strategy}

AR-LoGates application provided user to use the markers in order to scan to get the output. Markers consists for inputs which is for input 1 and input 0 , while markers for gates have seven markers which is for AND gate, OR gate, NOT gate, NOR gate, NAND gate, XOR gate and XNOR gate.

Table 2. Markers for Inputs and Logic Gates

\begin{tabular}{clcl}
\hline Marker & \multicolumn{1}{c}{ Description } & Marker & \multicolumn{1}{c}{ Description } \\
\hline 0 & $\begin{array}{l}\text { Marker for input which } \\
\text { is green color for input } \\
1(\mathrm{ON}) .\end{array}$ & $\begin{array}{l}\text { Marker for input which } \\
\text { is red color for input } 0 \\
\text { (off). }\end{array}$ \\
\end{tabular}

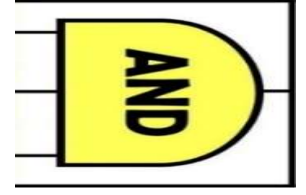

Marker for AND gate which is yellow color.

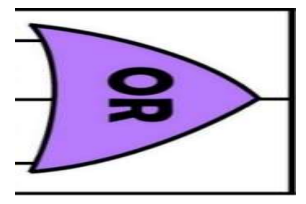

Marker for OR gate which is purple color.
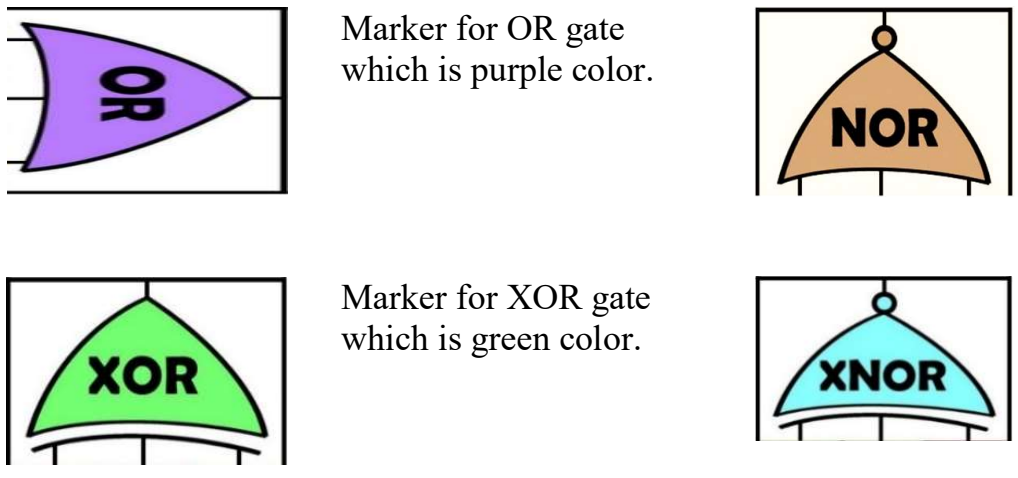

Marker for XOR gate which is green color.

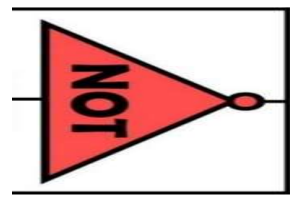

Marker for NOT gates which is red color.
Marker for NOR gate which is brown color.

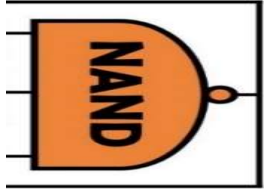

Marker for NAND gate which is orange color.

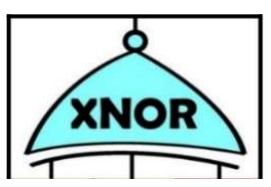

Marker for XNOR gate which is blue color. 
Nurul Hidayah Rahani, Aldrin Aran Bilong, Muhammad Rafiq Mat Suruji, Ismail Yusuf Panessai.

For using this Augmented Reality application, the important thing is that user must have the marker to scan. Table 2 shows the list of marker-based used in order to create the circuit and get the output. User need to print the marker to use with.

- User need to make sure the marker is well in shape in order to get the proper output and need to prepare more marker for input where this circuit is using three inputs for logic gate.

- User need to arrange the three inputs marker beside the gate marker properly in order to get the right answer.

- Then, user can scan the marker that already well arrange and get the answer in bulb shape.

- For 0 output, the bulb will turn grey in color, while the bulb will turn in color based on the gate color for the output 1 .

\subsubsection{Hierarchical Navigation}

In order to make the application being more structured and organized well, hierarchical navigation structure was followed. Figure 3 shows the AR-LoGates Apps navigation structure which is being important to make the user easily understand the application.

\subsubsection{Activity Diagram}

Based on Figure 4, activity diagram is basically a flowchart to represent the flow of the application from one activity to another activity. The activity can be described as an operation of the apps system that's being important in order to describe the dynamic aspect.

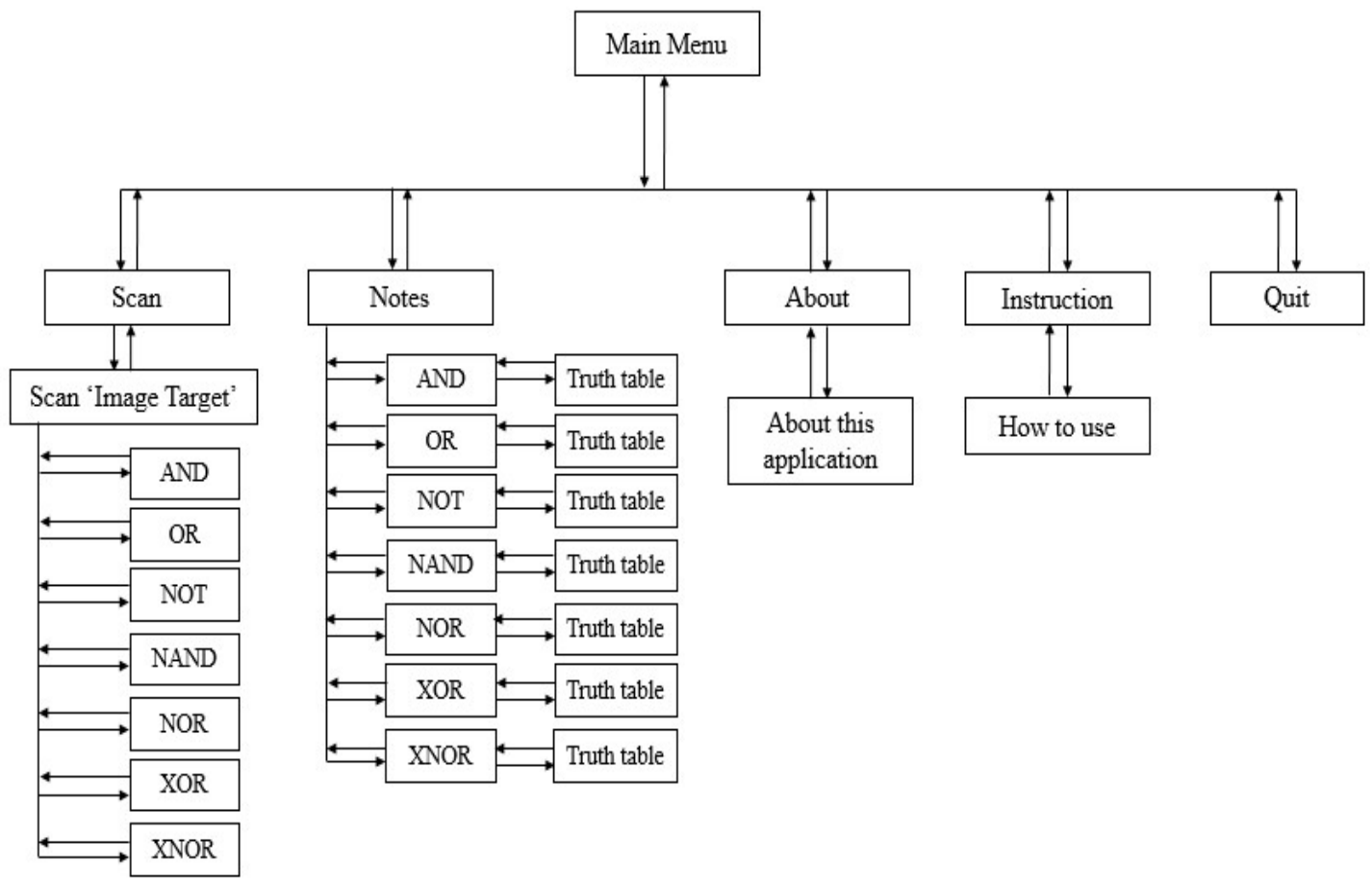

Figure 3. Hierarchical Navigation 


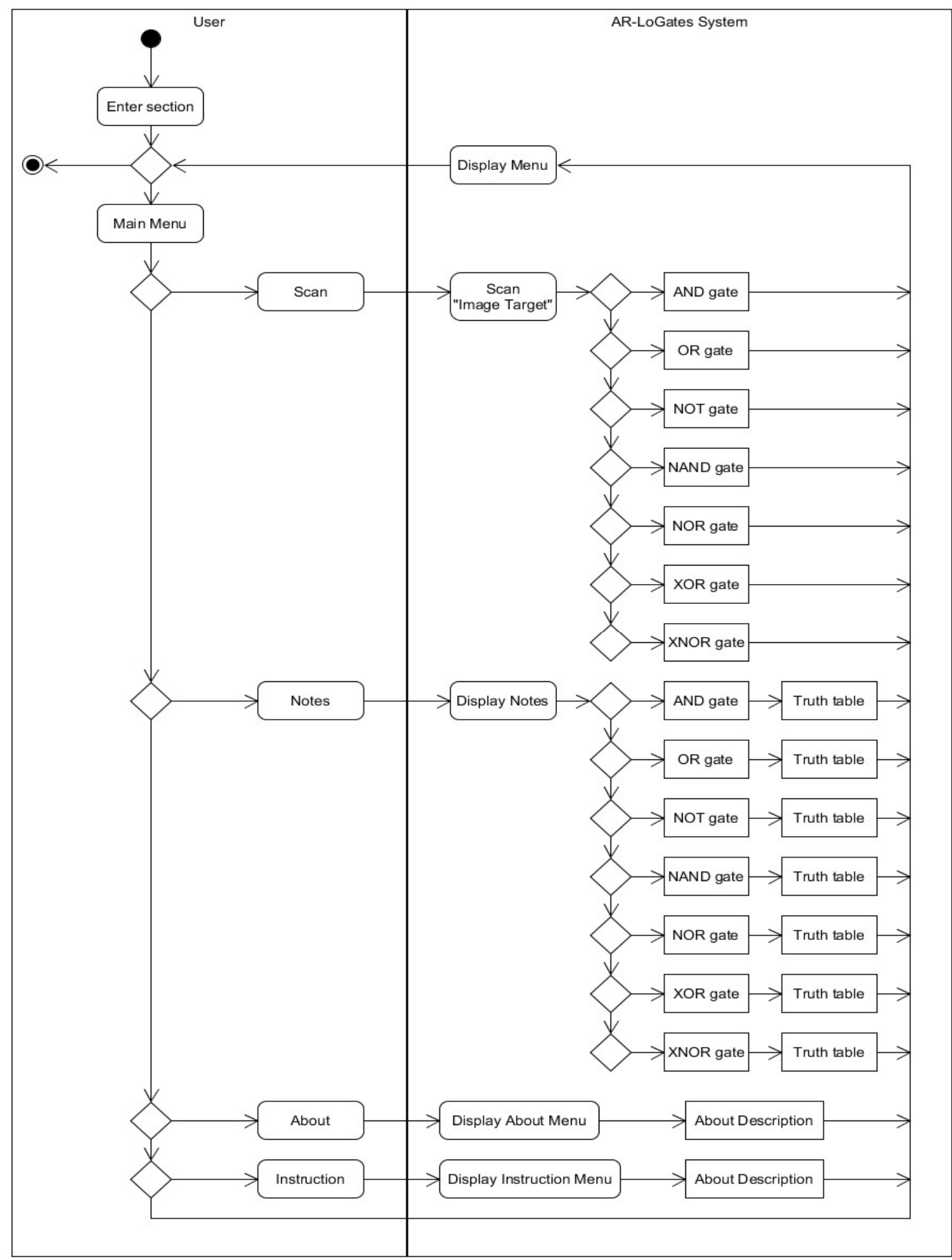

Figure 4. Activity Diagram

\subsection{Development Phase}

Development phase is the third phase after design phase which is important regarding to develop the product of AR-LoGates application by following ADDIE model. Development is where the process of integrate the instructional design and technology requirement within using the software in development 
Nurul Hidayah Rahani, Aldrin Aran Bilong, Muhammad Rafiq Mat Suruji, Ismail Yusuf Panessai.

AR-LoGates: Learning Logic Gates Using Augmented Reality.

International Journal of Multimedia and Recent Innovation, vol. 2, no. 1, pp. 26-44, March 2020. DOI: 10.36079/lamintang.ijmari-0201.81

of the project. Hence, the development phase is where all the instruction, media, supporting documentation, and appropriate software are prepared to meet the objectives.

Table 3. Activity Diagram Description

\begin{tabular}{|c|c|}
\hline Function & Description \\
\hline Main Menu & $\begin{array}{l}\text { Main menu is the first scene that will display when the user opens the } \\
\text { application. It's consist of } 5 \text { button which are scan button, notes button, about } \\
\text { button, instruction button, and quit button. }\end{array}$ \\
\hline Scan & $\begin{array}{l}\text { This function is where the user will access to the scan scene to start create the } \\
\text { circuit of the logic gates. Once the user arrange the marker, user need to scan in } \\
\text { order to get the output. }\end{array}$ \\
\hline Notes & $\begin{array}{l}\text { Provided the notes and truth table for the three inputs of the AND gate, OR gate, } \\
\text { NOT gate, NAND gate, NOR gate, XOR gate, and XNOR gate. }\end{array}$ \\
\hline About & Provided the description on what is this AR-LoGates application is about. \\
\hline Instruction & Provided the instruction on how to use AR-LoGates application. \\
\hline
\end{tabular}

In development phase, developer will design the interfaces, write the codes, and preparing for the testing. The software using in this phase is Unity 3D, Visual Studio, Android Studio, and Vuforia software. Through this phase, the development of this application is follow all the requirement needed and specification of the project based on the storyboard that has been design in design phase. If there are errors and defect of this application while in this phase, it will be fixed immediately. Development phase also included the programming which is for purpose and function of the user interfaces.

Table 4. Examples of Testing Result for AR of NOT gate

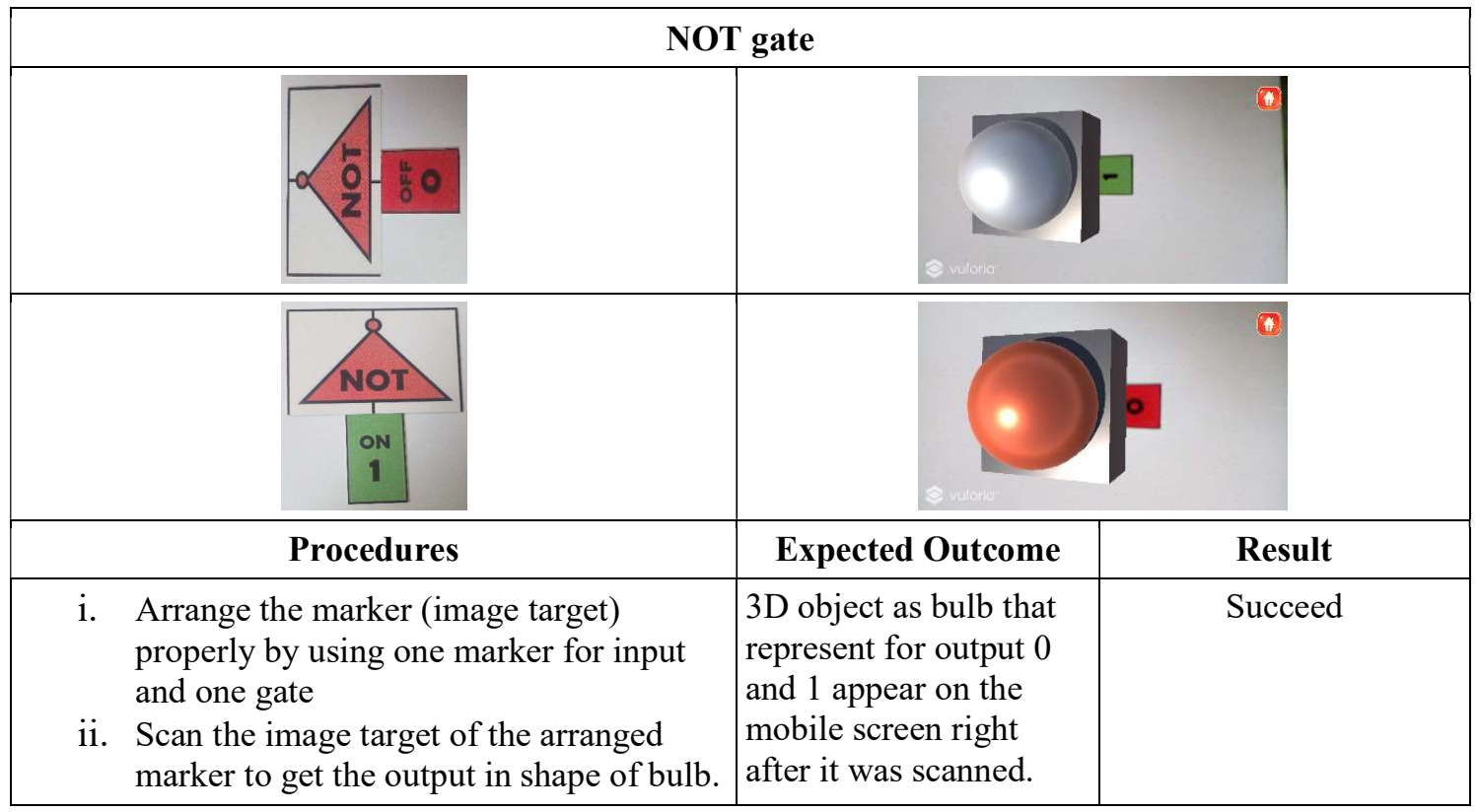

4.4. Implementation Phase

In implementation phase, once the application was implement into the mobile device, the test will be 
run based on the instructional goal of the module. This phase is to make sure that all the applications' function run smoothly as required in order to support and maintain the instruction based on usability, functionality, and its accessibility.

The testing is involved the research scope as the target user to test the mobile apps. The procedures of testing whether the application is well functioning or not are shown as in Table 4 and 5.

\subsection{Evaluation Phase}

In evaluation phase, developer carried out the pre-test and post-test in order to get the average improvement mark and used questionnaire survey to collect the feedback from the respondents (target user) after they used AR-LoGates application.

Table 5. Testing Result for AR of AND Gate



The test and questionnaire were distributed to 30 respondents for students from Diploma of Computer Science in Sultan Idris Education University. The questionnaire survey divided by three section of testing which measures by Graphic User Interface (GUI), Contents, and Usability in terms of effectiveness, efficiency, and satisfaction.

The results of the test and questionnaire that collected, the developer analyze the data result to gain the percentage of the finding results of AR-LoGates application. The analysis of these sections are justified in detail at the next chapter of research finding. 


\section{Result and Analysis}

After finished the prototype of this application, it need to be tested by user to determine the specification and requirement of the application is as expected and followed the specification. This project evaluated by carried out the pre-test, post-test and questionnaire. The evaluation involved 30 respondents from Diploma students in Science Computer who taking subject MTN 3013, group B (Computer Architecture and Organization). Pre-test and post-test is carried out to find the students percentage improvement when they are using this application. The prepared questionnaire was based on Theory of Technology Acceptance Model (TAM).

The pre-test was given to the respondents before they use this application. Then the developer prepared the marker for respondents and gave them the link of the application so that the student need to download to use it.

The respondents were given a week to use the application in order to test the application and understand more about the topic. After a week, the students need to take the post-test in order to find out the students' percentage improvement of understanding for using the application.

The evaluation questionnaire was given to the respondents after they were used the AR-LoGates Apps. The evaluation has three parts which is evaluate the Graphic User Interfaces (GUI), contents and the usability based on the effectiveness, efficiency, and the satisfaction of the application.



Figure 5. Interest in Technology

Based on Figure 5, the result shows that $80 \%$ from the respondents are interested in technology while the other $20 \%$ respondents only had moderate interest in technology.

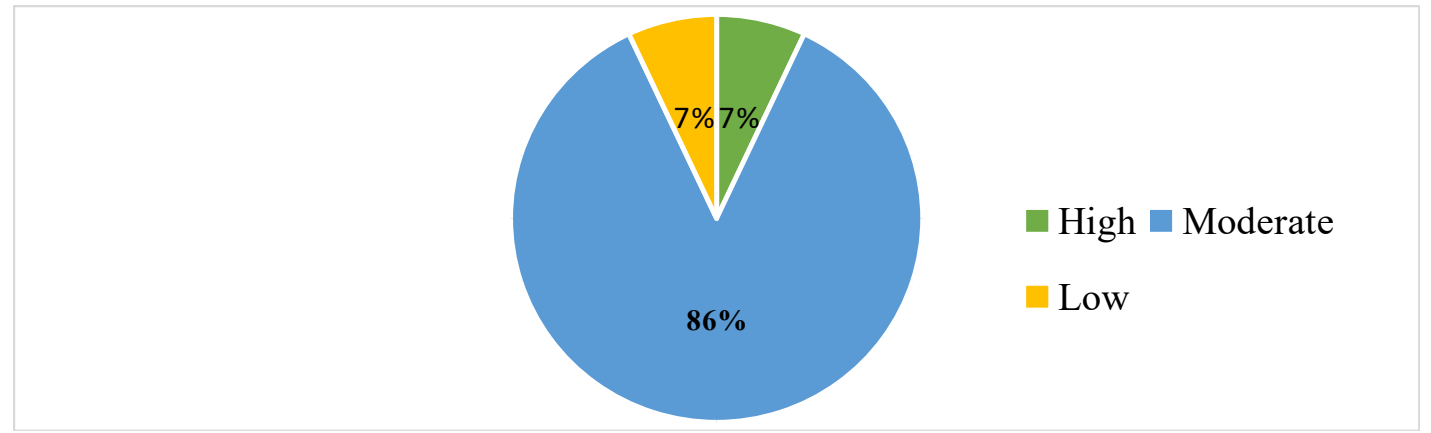

Figure 6. Knowledge about Logic Gate

In order to evaluate the respondents, the questionnaire consist of Section A which is about the respondent background. This section provided the question that is interest in technology, knowledge about logic gate, and interest in logic gate topic. 
Based on Figure 6 , the result shows that $86 \%$ from the respondents have high knowledge about logic gate topic. While the rest $7 \%$ respondents have moderate knowledge and other $7 \%$ respondents have low knowledge about logic gate.

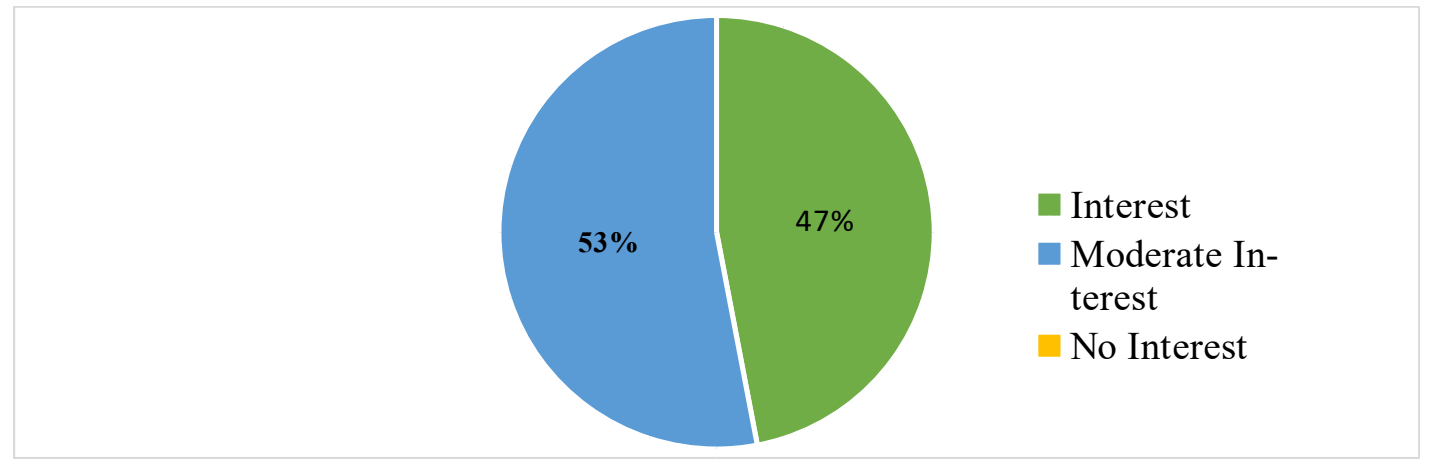

Figure 7. Interest in Logic Gates Topic

Based on Figure 7, result shows that 53\% from the respondents had interest in logic gate topic while the other $47 \%$ of respondents only had moderate interest in logic gate topic.

ə any experience using Augmented Reality Application

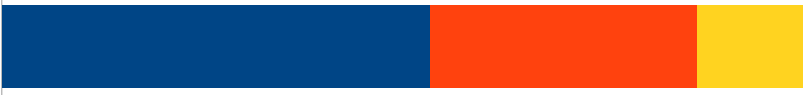

Do you know about the term 'Augmented Reality'?

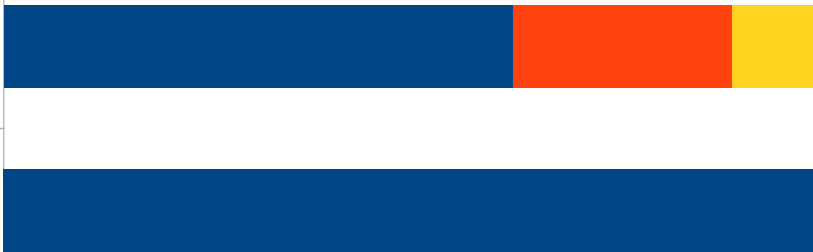

Do you know or ever used any mobile application?

Do you own a smartphone or a tablet?

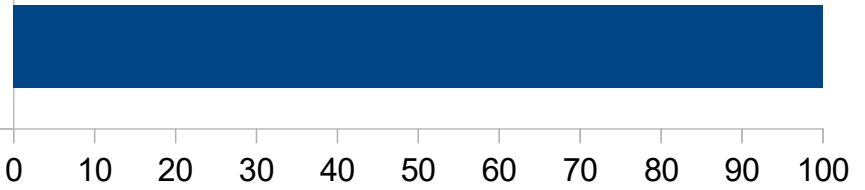

Yes $\square$ No $\quad$ N/A

Figure 8. General Question

In section $\mathrm{B}$ of the questionnaire, consist of four general question. The question is about smartphone or tablet ownership, experience in using any mobile application, knowledge on term of 'Augmented Reality', and the last question is about having any experience using augmented reality application.

Based on Figure 8, for the first and second question, 100\% respondents answered yes for the question 'do you own a smartphone or a tablet?' and 'do you know or ever used any mobile application?'. For the question 'do you know about the Augmented Reality term?', 63\% respondents answered yes, 27\% respondents answered no, while the rest $10 \%$ respondents answered N/A for that question.

Section C of the questionnaire consist of questions about Graphic User Interface (GUI) which is the 
interfaces that provided in the AR-LoGates application. The questions are about the interesting of the interfaces of the application, readability and understandability of the word provided in the application, understandable of the $3 \mathrm{D}$ objects, provided navigation button, and the design of the marker-based.

he design for marker-based are suitable and interesting?

¿d navigation button being easy to use and understand?

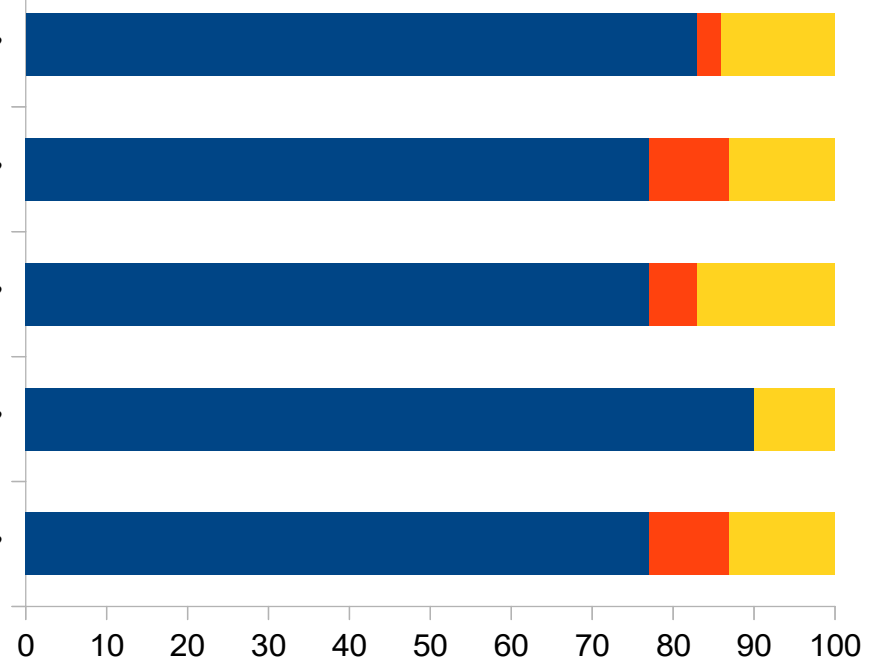

Does the 3D objects are clear and understandable?

Is the words are easy to read and understand?

Does the interfaces of application are interesting?

$\square$ Yes $\square$ No $\square$ /A

Figure 9. Graphical User Interface (GUI)

Based on Figure 9, the result shows $77 \%$ respondents answered yes for the interesting of the applications' interfaces, $10 \%$ answered no, and $13 \%$ answered N/A. For the question is the words are easy to read and understand?, $90 \%$ answered yes, while the rest $10 \%$ answered N/A. For the question about the $3 \mathrm{D}$ objects are clear and understandable, $77 \%$ respondents answered yes, $6 \%$ answered no, and $17 \%$ answered N/A. $77 \%$ respondents answered yes for the question of the navigation button provided being easy to use and understand, while 10\% answered no, and 13\% answered N/A for that question. For the marker-based design question, $83 \%$ respondents answered yes, $3 \%$ answered no, and the rest $14 \%$ respondents answered N/A.

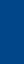

1e note provided is appropriate and ease to understand?

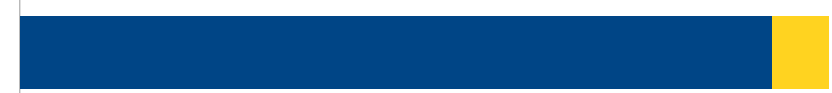

Is the $3 \mathrm{D}$ object are suitable to the topic of logic gates?

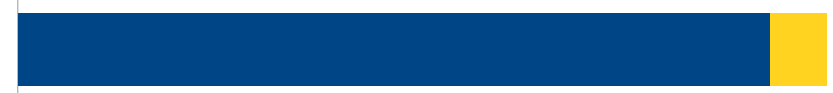

เ are unique compared to just using note and text book?

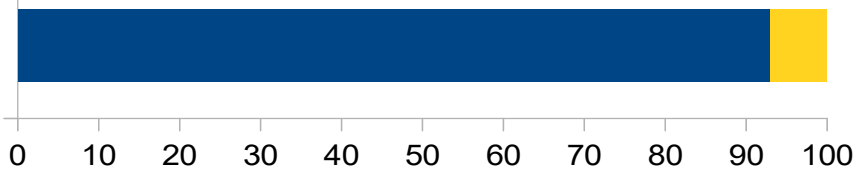

Yes $\square$ No $\square$ /A

Figure 10. Contents 
Section D of the questionnaire consist of questions about the contents that provided in the ARLoGates application. The questions are about the learning style of the application are unique compared to just using note and text book, the suitability of the 3D objects to the logic gates topic, the provided notes are appropriate and ease to understand, and the last question is about the instruction provided are clear and details to user use this application.

Based on Figure 10, the result shows that $93 \%$ respondents answered yes and $7 \%$ answered N/A for the learning style of the application is unique compared to just using note and text book. For the question of the suitability of $3 \mathrm{D}$ object to the logic gates topic and provided notes is appropriate and ease to understand, 93\% respondents answered yes and 7\% answered N/A respectively. For the forth question about provided instruction is clear and details to user use the application, $93 \%$ answered yes, while the others $7 \%$ answered N/A.

improve my learning style and productivity in learning
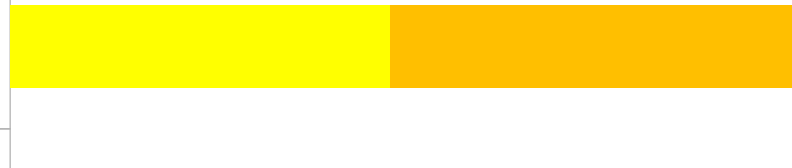

improve the level of understanding for logic gate topic

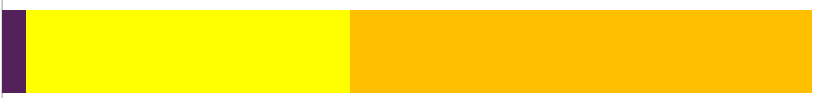

This application attract user to learn about logic gate

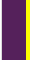

This AR application is suitable for learning this topic

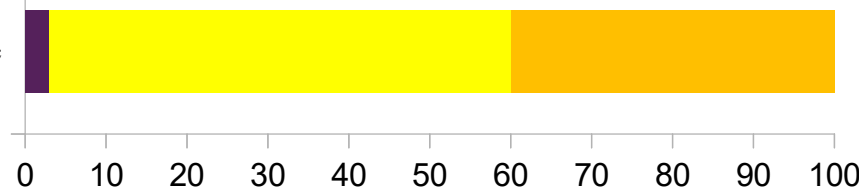

$\square$ Not Agree $\square$ Agree $\square$ Strongly Agree

Figure 11. Usability in Term of Effectiveness

Based on Figure 11, the result shows about the usability in term of effectiveness. For the question of suitability of this application to the learning topic, $3 \%$ respondents answered not agree, while $57 \%$ respondents answered agree and $40 \%$ answered strongly agree with that statement. For the statement of the application able to attract user to learn about logic gate, 3\% respondents answered not agree, $37 \%$ answered agree and the rest $60 \%$ respondents answered strongly agree. The next statement is about the application able to improve the level of understanding for logic gate topic, $3 \%$ respondents answered not agree, $40 \%$ answered agree, while the others $57 \%$ respondents answered strongly agree. The last question in term of effectiveness is about the application can improve the learning style and productivity in learning, $47 \%$ respondents answered agree while the rest $53 \%$ respondents answered strongly agree for that statement.

Section E from the questionnaire consist of usability question which is in term of effectiveness of the application to the target user, efficiency and the satisfaction of the application.

Figure 12 shows the results of the usability in term of efficiency. The first statement provided is about the application is well functioning, $60 \%$ respondents answered agree and $40 \%$ answered strongly agree. For the statement of the applications' scanner work properly, $67 \%$ respondents agree while $33 \%$ respondents strongly agree with that statement. The last statement is about the application take too much time in order to scan the marker-based, $10 \%$ respondents strongly agree and $33 \%$ agree for that statement, while $43 \%$ not agree and $13 \%$ strongly not agree that the application take too much time to scan the marker-based. 


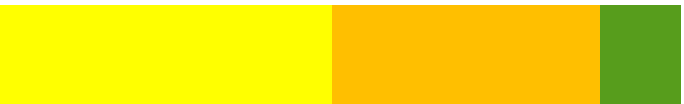

The scanner of this application work properly

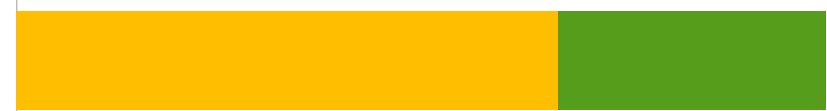

This application is well functioning

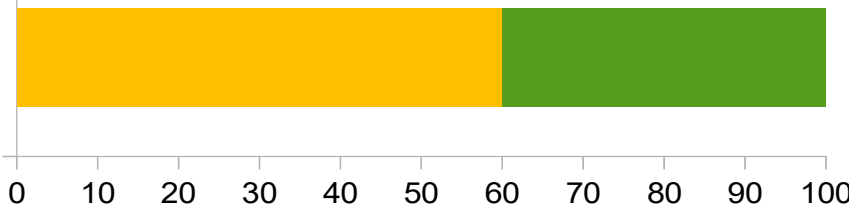

Strongly Not Agree

Not Agree $\square$ Agree $\square$ Strongly Agree

Figure 12. Usability in Term of Efficiency

Figure 13 shows the results of the usability in term of satisfaction. 50\% respondents agree and other $50 \%$ respondents strongly agree that this application is being fun to use. As overall, $47 \%$ agree and $53 \%$ strongly agree that this application being very useful in their learning. For the statement preferable the student using this application in the process of learning, $43 \%$ respondents agree and $57 \%$ respondents strongly agree that they are prefer using this application in learning. The last statement, $40 \%$ respondents agree and $60 \%$ respondents strongly agree that the application can help students in learning and able to make the learning skills more interesting.

ng and able to make the learning skills more interesting

$y$ prefer using this application in the process of learning

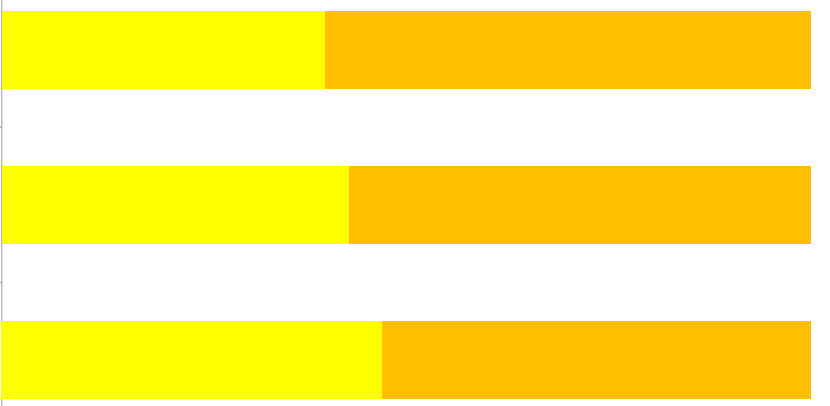

This application being fun to use

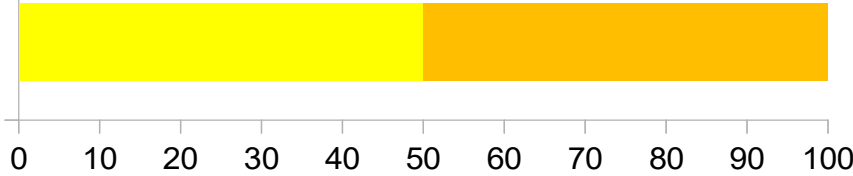

Not Agree $\square$ Agree $\square$ Strongly Agree

Figure 13. Usability in Term of Satisfaction 
In order to get the improvement percentage of student understanding for using AR-LoGates Apps, the pre-test and post-test was carried out. The test was given to the respondents which is the target user in order to achieve the objective of the research.

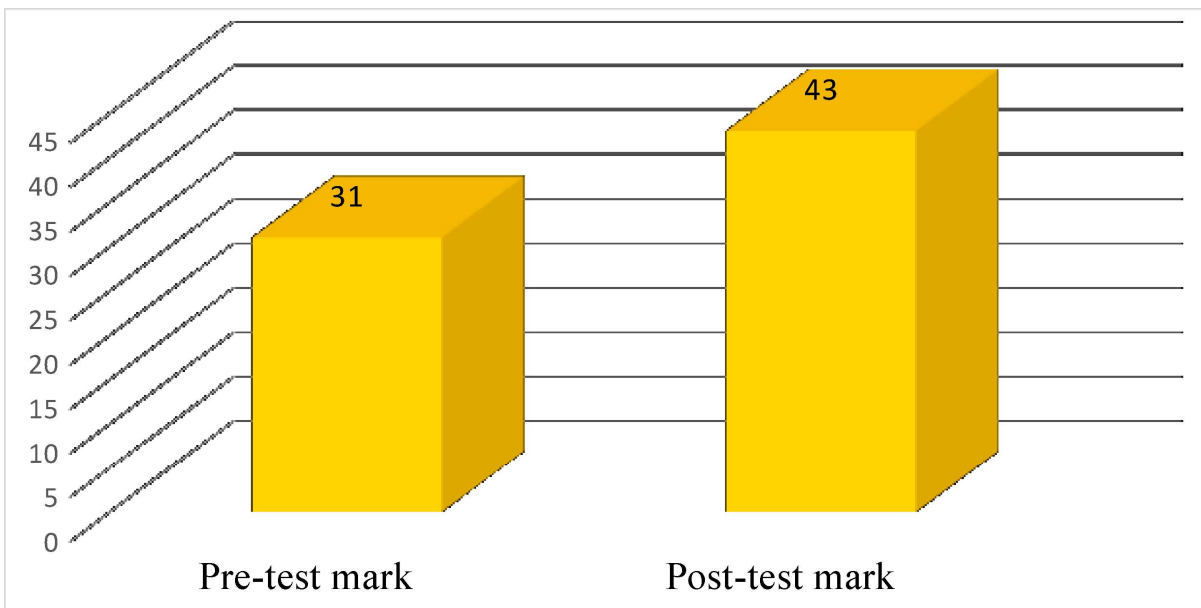

Figure 14. Average Improvement Percentage of Respondents

Based on Figure 14, the result shows the average of the improvement percentage of the mark. For the pre-test, average mark for respondents is 31 while the average mark for post-test is 43 mark. From the test, that average value has proved that the respondents achieved the improvement when using ARLoGates Apps in studying in order to make them more understanding.

The finding from the questionnaire has proven this research had achieved the research objectives and all the research question that has been answered. The developer built this product into mobile application to facilitate the users as the main purpose. Hence, the contribution of this project is the implementation and evaluation phase where there have assigned in improving the product.

Once the research has been done, developer found that AR-LoGates apps has a good reception from target user which is the student of Diploma in Science Computer which taking Computer Architecture and Organization subject in logic gate topic. The first objective which is to investigate the use of AR technology to attract interest of students in learning Computer Organization and Architecture subject has been achieved where AR-LoGates application able to attract interest of students to learning logic gates topic. Second objective that is to design logic gate circuit which able to embed in AR technology is success which this application able to use in mobile application and ease the user to use.

The third objective is to develop logic gate circuit using AR technology. The development of ARLoGates application is started with SRS documentation, SDD documentation in order to develop complete application. The last objective is to evaluate the AR technology of logic gate circuit in terms of Graphic User Interface, Contents, and Usability (effectiveness, efficiency, satisfaction). By evaluation, the results had shown that the application is evaluated by the respondents and gain the overall average of improvement mark. The average for pre-test is 31 while the post-test mark is 43 .

After the study was conducted intensively throughout the semester, researchers were able to identify the contribution of this application to the community and the field of Computer Architecture and Organization. Contribution to society is the existence of this AR-LoGates Apps can help improving students' knowledge and ease to understanding besides this application provide a hands-on and practical experiences for classroom lessons by using AR technology. However, this AR-LoGates Apps demonstrates that AR technology has the ability to enhance meaningful learning and make a powerful connection of reality with digital content that have a positive impact for education in Computer Architecture and Organization subject.

For the recommendation of future work, developer has found that AR-LoGates Apps need some improvement based on the product testing and feedback from the questionnaire in order to make it better 
Nurul Hidayah Rahani, Aldrin Aran Bilong, Muhammad Rafiq Mat Suruji, Ismail Yusuf Panessai.

AR-LoGates: Learning Logic Gates Using Augmented Reality.

International Journal of Multimedia and Recent Innovation, vol. 2, no. 1, pp. 26-44, March 2020. DOI: 10.36079/lamintang.ijmari-0201.81

in future. This AR-LoGates can help improving students' knowledge and skills in Computer Architecture and Organization subject especially in logic gate topic.

\section{Conclusion}

The content of this application could be improve in order to make user able to create combination circuit and improve the difficulties of the circuit. Besides that, this application also can be added the quiz or question section where to provide the user some exercise while learning. In order to make this application being more interesting, developer could add the games related to this logic gate topic. In future commercialization, AR-LoGates Apps which is AR application have a potential commercialization as a teaching and learning tool in secondary school for subject related to logic gate. Besides, it has potentially to be commercialization as it has widely usage in higher institutions, polytechnics, community colleges, schools, and vocational college.

Nowadays, this application can be implement in another operating system such as iOS due to the increasing of the number of users using iOS system. In today's technology, iOS is one of the wellknown operating system besides Android.

In conclusion, this AR-LoGates Apps has showed that it is necessary product by receiving a good reception from target user which is the diploma students of Science Computer from Sultan Idris Education University. The usage and combination of two technologies which is 3D and augmented reality were really interesting in process of teaching and learning. This application also able to enhance the traditional forms of teaching and learning in order to improve students' knowledge and interest about logic gate. In addition, this application could encourage students to think critically and creatively which improves their understanding and experiences using technology while learning. Besides that, this application does not require internet connection whenever it use. The expected outcome of this project are develop successfully as planned, but it still has some weakness according to the result obtained from the findings. However, the weakness will be improved in future.

\section{References}

[1] R. T. Azuma, "A Survey of Augmented Reality," Presence: Teleoperators and Virtual Environments, vol, 6, no.4, pp. 355-385, 1997. doi: 10.1162/pres.1997.6.4.355

[2] R. Palmarini, J. A. Erkoyuncu, R. Roy, and H. Torabmostaedi, "A systematic Review of Augmented Reality Applications in Maintenance," Robotics and Computer-Integrated Manufacturing, vol. 49, pp. 215-228, 2018. doi: 10.1016/j.rcim.2017.06.002.

[3] S. Cai, X. Wang, and F. K. Chiang, "A case study of Augmented Reality simulation system application in a chemistry course," Computers in Human Behavior, vol. 37, pp. 31-40, 2014. doi: 10.1016/j.chb.2014.04.018.

[4] R. Palmarini, J. A.Erkoyuncu, R. Roy, and H. Torabmostaedi, "A Systematic Review of Augmented Reality Applications in Maintenance," Robotics and Computer-Integrated Manufacturing, vol. 49, pp. 215-228, 2018. doi: 10.1016/j.rcim.2017.06.002.

[5] T. Jeřábek, V. Rambousek, and R. Wildová, "Perceptual Specifics and Categorisation of Augmented Reality Systems," Procedia - Social and Behavioral Sciences, vol. 191, pp.1740 1744, 2015. doi: 10.1016/j.sbspro.2015.04.419.

[6] J. M. Mota, I. Ruiz-Rube, J. M.Dodero, and I. Arnedillo-Sánchez, "Augmented Reality Mobile App Development for All," Computers \& Electrical Engineering, vol. 65, pp. 250-260, 2018. doi: 10.1016/j.compeleceng.2017.08.025.

[7] T. K. Neo, M. Neo, and W. J. Kwok, "Engaging Students in a Multimedia Cooperative-Learning Environment: A Malaysian Experience in Same places, different spaces," Proceedings ascilite Auckland, 2009.

[8] P. Mahale, and S. Yeddu, "Android-based Augmented Reality to Enhance Education System," International Journal of Computer Applications, vol. 146, no. 6, pp. 18-21, 2016 doi: 10.5120/ ijca2016910790.

[9] L. Rentzos, S. Papanastasiou, N. Papakostas, and G. Chryssolouris, "Augmented Reality for Human-based Assembly: Using Product and Process Semantics," IFAC Proceedings Volumes, vol. 46, no. 15, pp. 98-101, 2013. doi: 10.3182/20130811-5-us-2037.00053

[10] N. F. Saidin, N. D. A. Halim, and N. Yahaya, "A Review of Research on Augmented Reality in Education: Advantages and Applications," International Education Studies, vol. 8, no.13, 2015. 
Nurul Hidayah Rahani, Aldrin Aran Bilong, Muhammad Rafiq Mat Suruji, Ismail Yusuf Panessai.

AR-LoGates: Learning Logic Gates Using Augmented Reality.

International Journal of Multimedia and Recent Innovation, vol. 2, no. 1, pp. 26-44, March 2020. DOI: 10.36079/lamintang.ijmari-0201.81

doi: $10.5539 /$ ies.v8n13p1.

[11] C. H. Tsai, and J. Y. Huang, “Augmented Reality Display Based On User Behavior," Computer Standards \& Interfaces, vol. 55, pp. 171-181, 2018. doi: 10.1016/j.csi.2017.08.003.

[12] N. Aldoobie, “ADDIE Model,” American International Journal of Contemporary Research, vol. 5, no. 6, pp. 68-72, 2015.

[13] H. M. Mawardi, S. Anitah, and Asrowi," The Model of Instructional Design Based on SelfRegulated Learning using Modular Object Oriented Dynamic Learning Environment (MOODLE)," Journal of Education and Practice, vol. 5, no. 22, pp. 131-140, 2014. 